the modern institution of the custom of calling over the names of the pupils in the different classes,--certificntes being given to those only who attend regularly, or, rather, to those whose friends slip in their cards for them, for it is a very common thing for one student to hand in six cards at a time.

Towards the close of the pamphlet the anthor makes the following curious statement:-

"The professors of the University of Edinburgh are well aware that they have been granting medical degrees uithout any LEGAL authority. If an Edinburgh degree was questioned in a court of law, particularly in England or Ireland, there cannot he the least doubt that it would be found not worth one farthing, and could not be sustained. This opinion, which many sound lawyers entertain, is founded on the following fact, - that the University of Edinburgh has no charter.-Among the Scotch universitics she stands alone, all the others having charters."

The pamphlet has created an extraordinary sensation throughout Edinburgh. It has been read with avidity by practitioners andi students, and the statements it contains must produce a powerful impression in every other part of the United Kinglom. If those statements admit not of refutation, the professors will scon have to exclaim with Othello, that their " occupation's gone."

\section{TIIE I.ANCET.}

Londoa, Saturday, Feb. 8th, 1834.

Mr. Warburton, on Tuesday last, the first day of the session, gave notice of a motion for Tuesday next, for the appointment of a Coмmrтт:e to inquire inco the state of medical education and practice throughout the United Kingdom of Great Britain and Ireland. This early manifestation of zeal on the part of Mr. WArBurToN, will afford renewed confidence to the medical reformers residing in all parts of the empire.

\footnotetext{
$\longrightarrow$
}

Ir may be presumed that one of the first subjects connected with medical education that will engage the attention of the Parliamentary Commitee of INQURRY, will be the investigation of the medical discipline and capabilities of our several Universities. At page 749 , will be found a short notice, furnished by our Edinburgh correspondent, of a pamphlet which has just appeared in the north, devoted to an explanation of the public and private systems of teaching a knowledge of modicine in Edinburgh, and exhibiting also some account of the modes in which the process of graduation has been accomplished, both there and in the sister institution of St. Andrew's. Having perused this pamphlet with considerable care, we only discharge a public duty in recommending it to general attention. The abuses which are laid open in its pages are of frightful extent, and of most odious character,-partaking, in the fullest manner, of the fraudulent abominations which have been so frequently perpetrated by the chartered medical corporations of London.

It is alleged by the writer that the University of Edinburgh is without a charter, and that the medical degreo granted by that body is therefore only an honorary distinction, entirely divested of any legal privilege. St. Andrew's, it seems, hopes to secure, by the adoption of a more liberal system, a larger share of business in the trade of degree-mongering. Nothing could be more opportune than this contention between the two Universities, - a struggle, as far as the belligerents are concerned, quite divested, we conceive, of any spirit of national liberality or patriotism. The duty of the Legislature with regard to the Universities and chartered medical institutions of every description, is simple and of easy performance. 
In establishing Tripartite Faculties or MEdicine for regulating the practice, and confirming the rights of medical practitioners on precisely similar conditions throughout the united kingdom, it should be decreed that all the universities and colleges may grant degrees and diplomas as heretofore, but that in no instance shall a man be entitled to practise medicinc, after the passing of the law, without unlergoing a public examination before the proper authorities of one of the tinree divisions of the Narroval FacUlty.

Thus the diplomas, degrees, and certificates would be left to confer on their poszcssors a share of whatever reputation might belong to the institution by which they were issued. The Facunty, in evcry instance, would thus present a protecting bar between the community on ; the onc side, aud ignorant teachers aud : fraudulent examiners on the other. In the operation of such a system we instantly observe what would be its effect on medical education. The admission of all candidates to an examination before the FAcc ITY, without reference to persons or places from whom or where their knowledge had been'derived, would break down in the most effectual manner the scandalous monopolies of chartered teachers, and as the scrutators would be compelled, by law, to observe a strict uniformity in the leacling principles of the knowledge demanded from candidates for the right to practise, the most genial spirit of emulation would be diffused amongst the teachers occupying chairs, and a uniform system of medical education necessarily enforced.

Tre rice question is one of extraordinary interest and importance, not only to the people of England, but to the inhabitants of every country in which rice is consumed as an aricle of ordinary food.
If the subject be regarded as presenting only a simple proposition to the mind, even in that case the general application of the inference necessarily deducible from the facts submitted to scrutiny, must extort from every impartial inquirer an involuntary acknowledgment of the advantages which the discovery of Dr. Trreen must confer on mankind. When, however, the question is taken in a more enlarged sense,- -when it is considered with reference to diseascd grain in general, it becomes impossible to form the remotest conjecture of the sum of human life that may be preserved from the detection of a poisonous priuciple in the farinaceous products of ccrtain culmiferous plants.

As rice forms the chief article of food of many eastern nations, it is boldly alleged that this well-known fact rednces the inductive theory of Dr. Truter into a nucre bypothesis, aul converts all his positive statements, relative to the malignant diseas's engendered by a diet consisting of vitiated grain, into speculative, gratuitous assumptions. There is no denying either the existence or the importance of the fact in question, but then it disprores not one of the arguments advanced by $D_{1}$. TrTLER-it weakens not one of his conclusions-it shakes not in the slightest degree the clear and satisfactory evidence furnished by a host of respectable, disinterested witnesses. If it be a fact that millions of people subsist ajmost entirely on sound rice, is it not equally a fact that, since this subject was first intro" duced to the notice of the English public, an individual has died in London from having eaten unsound rice, almost as suddenly as though that person had partaken of a quantity of arsenic? Other facts have been elicited in London fully as corrobo. rative of the existence of a deleterious principle in rice which was not at all suspected to be of an inferior quality. Thus, if the fact be establisher in only a single 
instance that poisonous rice has destroyed human life, that fact cannot be controverted or weakened by proving that innocuous rice has preserved the lives of millions.

Let us, however, refer to a circumstance, bearing strongly on this view of the inquiry, the mention of which is not likely to interfere with our prejudices or interests. The grass lands of England sustain and fatten the finest flocks of sheep that are to be seen in the universe. Grass is the common, and, except during a month or two in the winter season, the only food of shecp. Now, what occasionally happens with respect to these hardy, docile animals? That when fed in certain pastures, numbers of them become the subject of a disease called the " rot." After wet seasons, this disease is known to be much more prevalent than after comparatively dry periods, in which vegetation las taken its natural healthy growth. Although this fact is armitted by every agriculturist, is it denied that grass is the ordinary food of sheep, and that it snstains and fattens millions of them annually? So is it with rice. It may, under certain circumstances, be productive of health and life, and yet, under adverse conditions of soil and grain, it may be capable of producing both disease and death.

In publishing the letter inserted at page 746 of this week's LA $\mathbf{~ C E T , ~ s i g n e d ~ " ~ J . ~ T ~ , " ~}$ we cannot refrain from observing, that it confirms in the fullest manner the allegations of Dr. Tytuen on points where the greatest incredulity prevailed amongst some of his hearers at the London Medical Society, and which appeared to be the least susceptible of proof. It is now certain that we have mills for polishing East India rice for the English market, close to the very walls of this metropolis. The letter of our correspondent has been properly authenticated.
Tre operation of vivisection was so admirably executed on the culprit MAcLEOD by Professor Grant, that we were fully prepared to witness the crawl of the reptile through every species of dirt, in order to escape from the skilful hand of its tormentor. The miserable viper is "biting at a file."

MACLEOD, incapable of supporting the cause of his employers by argument, has serlulously laboured to throw discredit on our statements, by attacking the " morality" of The LANCET, and in this his goodly operation, he has repeatedly accused this journal of "blasphemy," "falsehood," and "forgery."

With respert to the first cf these accusations, we have merely to observe that MACLEOD is utterly ignorant of the meaning of the word he employs; wherefore we have only to say to him on this hoal, " Judge not, lest thou be judged." of " falsehood," ThE LAvcet donbtless contains enough, since many of its pages exhibit the records of the proceedings of the Bats.

With respect to the third charge advanced against us by MACLEoD, viz., that of "forgery," it might, considering the character of our accuser, he dismissed as summarily as the other two accusations, but Macleod has now, for the first time, made a distinct reference to the circum. stance on which he proposes to ground that infamous calumny. "In THE LAN" CET of August the 7th, 1830, there is," quoth he, " a forged letter from Dr. Ramsiotham." Why accuse The Lanaet of "forgery" if the "forged "letter be "firom Dr. Ramsbotham ?" The blockhead meant, of course, that there was a "forged" letter in The LanceT, purporting to come "from Dr. Ramsbotham." This "forgery" MACLwOD states is " remarkable as being " actually acknowledged in the next " number to have been the workmanship 
" of the editor." It is necessary that we to the "Yellow Journal,"-a mode of exshould copy the squib in question, and pression which would scarcely have been the few lines that preceded it, in order recognised and printed in the now defunct that our readers may have an opportu- "Medical and Physical," it was stated in nity of forming sorne opinion of the ma- the introductory notice, that all that was lignity and stupidity which could found so not material to the story which the Docserious an accusation on so childish a cir- tor related, had been expunged. Of course cumstance. We copy the following para- it is useless to advance another word on graphs, therefore, verbatim, from page the subject; but we could not icfrain 745 of The Lancet, vol. 2, 1829-30.

Obstetric Society.-In a late number of THE LANCET we took occasion to inquire what had become of the "Obstetric Society." Dr. Ramsbotham, the hon. sec., has put forth a reply in the Yellow Journal for the present month. For the accommodation of our readers we have expunged a' that is no material to the stoory, but as the article thus abridged is still rather long, we must withhold comments until next week.

\section{To the Editor of the Fellow Journal.}

Sir,-As Tre Lancet appears to be rather restless on the subject of our Society, and as the members have no desire to encounter its point, I have been directed to furnish you with the following short account of our proceedings.

I am, Sir, yours, \&c.,

F. H. Ramsiotham, Hon. Sec. New Broad-Street, June 1, 1830.

from contributing another fact towards the development of the now fully-exposed cha. racter of MACLEoD,-of Roderick MacxEOD,-at one time time the organ of the BATs, but now reduced to the unenviable occupation of trumpeter of his own ill fame. What is to be thought, we ask, of the mind and feelings of that man who, on so silly a parody as the one just quoted, could seriously found a charge of "forgery," in the criminal sense of that accusation? As a censor of " morals," Rode. RICK MACLroD unquestionably stands alone in the world.

That no ill-feeling continued to disturb the peace of Dr. F. H. Ramsbotham's mind from the publication of the foregoing parody, may be inferred from the fact,

The publication of this self-evident that within six weeks after its appearparody having elicited an angry note from ance in The Lancre, Dr. Ramsbothay, Dr. RAmsbotham, disavowing the author- happening to be present with Mr. Lurr, ship of any address to the "Editor of the at one of the public meetings of the elec. Yellow Journal," - which no one in his tors of Middlesex, held during the canvass right senses could ever have thought of for the office of coroner, took an opportiattributing to him,-we appended to the nity, when the meeting was over, of assurDoctor's disclaimer the following lines, ing the Editor of this Journal (in which aswhich Macleod designates as the Editor's 'surance he was joined by Mr. Luke), with subsequent "acknowledgment" that he was the "forger" of the note.

[Did Dr. Ramsbotham ever see a puddle of the London Hospital, that he was in a storm? We shall instruct our "tran- wrong in supposing that those officers scriber of journals" not again to meddle with the Doctor's grammar, and instead of giving a point to his productions, to leave them pointless. The angry Doctor will excuse us for saying a few sharp things upon his Obstetrical Society shortly. -ED. L.]

Now, it will be observed, that, independently of the note having been addressed, reference to some allusion, in the speech
of Mr. WAKLEY, to he medical officers
of the London Hospital, that he was
wrong in supposing that those officers
were hos tile to him, and the Doctor con-
cluded the conversation by warmly shak.
ing Mr. WAKLEx by the hand. reference to some allusion, in the speech
of Mr. WAKLEY, to he medical officers
of the London Hospital, that he was
wrong in supposing that those officers
were hos tile to him, and the Doctor con-
cluded the conversation by warmly shak.
ing Mr. WAKLEx by the hand. reference to some allusion, in
of Mr. WAKLEY, to he medi
of the London Hospital, th
wrong in supposing that those
were hostile to him, and the Dod
cluded the conversation by warm
ing Mr. WAKLEY by the hand. 